John Carroll University

Carroll Collected

Physics

$10-25-2011$

\title{
Toward high-performance nanostructured thermoelectric materials: The progress of bottom- up solution chemistry approaches
}

Yixin Zhao

Jeffrey S. Dyck

John Carroll University

Clemens Burda

Follow this and additional works at: http:// collected.jcu.edu/phys-facpub

Part of the Biological and Chemical Physics Commons

\section{Recommended Citation}

Zhao, Yixin; Dyck, Jeffrey S.; and Burda, Clemens, "Toward high-performance nanostructured thermoelectric materials: The progress of bottom-up solution chemistry approaches" (2011). Physics. 3.

http://collected.jcu.edu/phys-facpub/3 


\title{
Materials Chemistry
}

Cite this: J. Mater. Chem., 2011, 21, 17049

www.rsc.org/materials

FEATURE ARTICLE

\section{Toward high-performance nanostructured thermoelectric materials: the progress of bottom-up solution chemistry approaches}

\author{
Yixin Zhao, ${ }^{a b}$ Jeffrey S. Dyck ${ }^{* c}$ and Clemens Burda $* a$ \\ Received 20th April 2011, Accepted 11th July 2011 \\ DOI: 10.1039/c1jm11727k
}

\begin{abstract}
Significant research effort has recently gone into the synthesis of thermoelectric nanomaterials through different chemical approaches since nanomaterials chemistry became a promising strategy for improving thermoelectric performance. Different thermoelectric nanocrystals, especially $\mathrm{PbTe}, \mathrm{Bi}_{2} \mathrm{Te}_{3}$ and $\mathrm{CoSb}_{3}$, with various compositions and morphologies have been successfully prepared by solvo/ hydrothermal, electrochemical, and ligand-based synthesis methods. Such nanoscale materials show not only substantial reduction in thermal conductivity due to increased phonon scattering at nanoscale grain boundaries and lower densities of phonon states but possibly also an enhancement in thermopower due to electronic quantum size effects. More recently, the notoriously low power factors of thermoelectric nanomaterials prepared by wet chemistry have been significantly improved by using an increasingly cross-disciplinary approach towards the bottom-up synthesis that combines expertise from chemistry, physics, and materials engineering. In this review, we discuss the recent progress and current challenges of preparing thermoelectric nanomaterials with solution-based chemistry approaches.
\end{abstract}

${ }^{a}$ Center for Chemical Dynamics and Nanomaterials Research, Department of Chemistry, Case Western Reserve University, 10900 Euclid Avenue, Cleveland,OH, 44106,USA. E-mail: burda@case.edu

${ }^{b}$ Department of Chemistry, Penn State University, University Park, PA, 16803, USA

'Department of Physics, John Carroll University, 20700 North Park Blvd., University Heights, OH, 44118,USA.E-mail: jdyck@jcu.edu

\section{Introduction}

Thermoelectrics have attracted much attention and effort of scientists and engineers for decades due to their applications as solid state heat engines which generate electrical power from a temperature difference or convert electrical power into cooling. However, their widespread applications are limited due to their low energy conversion efficiencies, ${ }^{1,2}$ which are directly related to

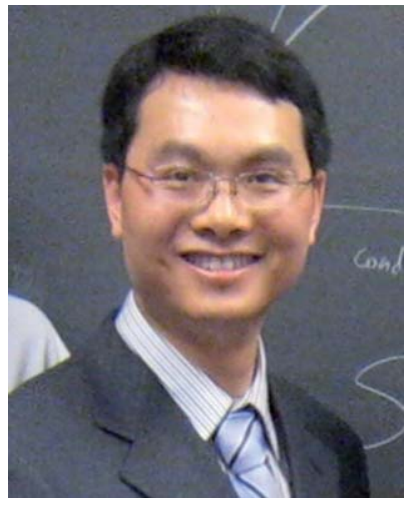

Yixin Zhao
Yixin Zhao received his BS and MS degree in Chemistry from Shanghai Jiao Tong University in China. He joined Case Western Reserve University in 2005 and worked as a graduate student at the laboratories of Professors Burda and Dyck on the project of thermoelectric nanomaterials and received his PhD degree in 2010. Currently, he is a postdoctoral in the Department of Chemistry at Penn State University, where he works with Professor Thomas E. Mallouk on solar fuel conversion.

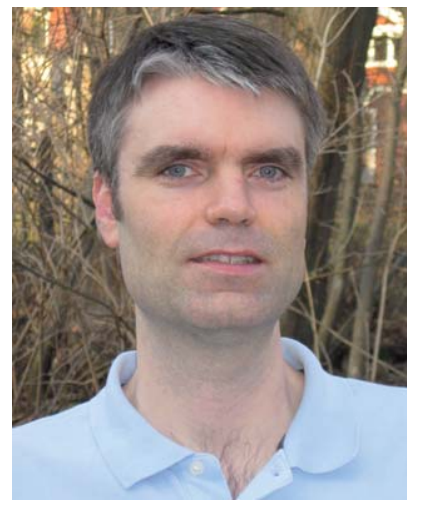

Jeff Dyck
Prof. Jeff Dyck obtained his PhD from Case Western Reserve University in 1999 in experimental condensed matter physics under the guidance of Prof. Kathleen Kash. He was a postdoctoral fellow at the University of Michigan with Prof. Ctirad Uher. Since 2003, he has been a faculty member in the Department of Physics at John Carroll University in Cleveland, $\mathrm{OH}$, where he is currently an Associate Professor. His research agenda focuses on electronic and thermal transport properties of novel materials and he has published fifty scientific papers. 
the figure of merit, ZT $=\left(S^{2} \sigma / \kappa\right) T=\left(S^{2} / \kappa \rho\right) T(S$ thermopower or Seebeck coefficient, $T$ temperature, $\sigma$ electrical conductivity, $\rho$ electrical resistivity and $\kappa$ thermal conductivity). ${ }^{3-7}$ The dimensionless ZT value of thermoelectric materials had been stagnant at around 1 for several decades. In the 1990s, Dresselhaus and Hicks at MIT proposed the concept of increasing ZT values of thermoelectrics through nanoengineering, based on their theoretical studies. ${ }^{8,9}$ This prediction has been realized for $\mathrm{PbTe} / \mathrm{PbSe}$ and $\mathrm{Bi}_{2} \mathrm{Te}_{3} / \mathrm{Bi}_{2} \mathrm{Se}_{3}$ heteronanostructures. ${ }^{10,11}$ Since then, optimism of significantly increasing ZT by nanoengineering has inspired the enthusiasm of scientists with different backgrounds, including chemists, to devote themselves to this challenging topic. There are two major strategies to fabricate thermoelectric nanomaterials: the top-down and bottom-up approaches. In top-down approaches, those traditionally optimized bulk materials are broken into micro- or nano-sized particles by ball milling or spin melting, which were demonstrated to be efficient approaches to improving ZT values. ${ }^{12-14} \mathrm{On}$ the other hand, the bottom-up approaches control the growth of nano-sized materials using different techniques, for example in the above cited breakthrough reports ${ }^{\mathbf{1 0 , 1 1}}$ heteronanostructures were prepared by the molecular beam epitaxy (MBE) technique. Solution chemistry approaches are an important part of bottomup methods, which has been widely applied in the preparation of other nanomaterials.

Historically, solution phase chemistry has not been involved in the preparation of thermoelectric materials as much as physical top-down approaches, simply because there was little contribution that could be provided by solution chemistry before the emergence of nanoscience and the development of nano-chemistry. The early successes in nano-engineering were however not suitable for bulk applications because these fabrication methods adopted highly sophisticated and expensive techniques such as molecular beam epitaxy and other advanced film growth methods. Solution chemistry approaches for preparing nanomaterials are less costly and are quite suitable for large scale production. Therefore, solution-based chemistry has evolved towards the nanoscale chemical synthesis of thermoelectric materials and the successful synthesis of various thermoelectric

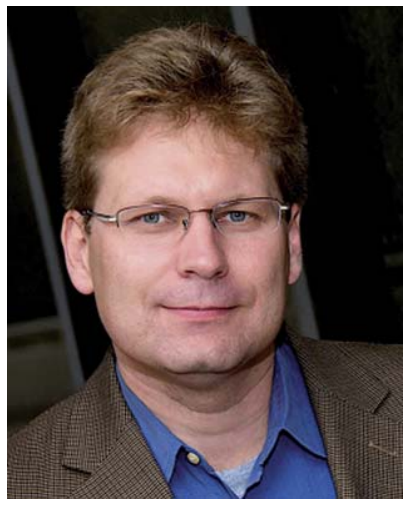

Clemens Burda
Prof. Burda obtained his PhD from the University of Basel, Switzerland. He was a postdoctoral fellow at the Georgia Institute of Technology with Prof. El-Sayed. Currently he holds a faculty position in Chemistry and Materials Science and Engineering at Case Western Reserve University, in Cleveland, Ohio, focusing on nanomaterials chemistry and laser spectroscopy. Prof. Burda is an editorial member for the International Journal of Nanotechnology, co-author of several book chapters, and lead author of over a hundred publications in the field of nanoscience. nanomaterials has been realized by a number of different chemical synthesis techniques. ${ }^{15-18}$

This review is not intended as an all-exhaustive review for all the exciting nanostructured thermoelectric materials research to date, which has recently been summarized by well-known experts. ${ }^{13,19,20}$ Instead, the purpose of this review is focused on highlighting some recent progress and discussing the role of solution phase chemistry in preparing nanostructured thermoelectric materials, which was for quite some time overlooked and underestimated in the research arena of thermoelectrics.

Due to the concerns of converting under high temperatures the nanostructures into bulk materials, most of the research focused on materials that have their maximum thermoelectric performance near or not too far above ambient temperature. These materials include IV-VI and V-VI chalcogenides such as PbTe, $\mathrm{Bi}_{2} \mathrm{Te}_{3}$ and their derivatives. By now, the most widely used solution chemistry approaches for thermoelectric nanomaterials synthesis include hydro/solvo-thermal, ${ }^{21-23}$ electrochemical, ${ }^{15,16,24}$ sonochemical $^{25-28}$ and ligand-based synthesis. ${ }^{18,29,30}$ The most commonly synthesized thermoelectric compounds are $\mathrm{PbTe}(\mathrm{Se})$, $\mathrm{Bi}_{2} \mathrm{Te}_{3}(\mathrm{Se})$ and $\mathrm{CoSb}_{3} \cdot{ }^{31}$

\section{Hydro- and solvo-thermal synthesis}

The hydro- and solvo-thermal synthesis method is a technique that crystallizes substances at elevated temperature and pressure in a sealed flask. The difference between hydro and solvo lies in whether the precursor solution is aqueous (hydro) or nonaqueous (solvo). A major benefit of this technique lies in its cost efficiency and simplicity compared to other methods. In addition, it produces highly crystalline nanopowders, in most cases without further need for calcination, and it makes doping of foreign ions relatively straightforward to realize, which is in this context very important for the adjustment of carrier concentrations in the thermoelectric materials. Last but not least, hydroand solvo-thermal methods make it possible to control the orientation and morphology of the desired nanomaterials, which would be an effective strategy to induce phonon scattering and hence increase the thermoelectric performance. ${ }^{32}$ Because of these advantages, hydro/solvo-thermal methods have been widely used in developing different thermoelectric nanomaterials over the past few decades.

$\mathrm{PbTe}^{33-37} \mathrm{Bi}_{2} \mathrm{Te}_{3}$ (ref. 22,35 and 38-44) and $\mathrm{CoSb}_{3}$ (ref. 45and 46) are the three most reported nanomaterials that are synthesized by hydro/solvo-thermal approaches. In a typical hydro/ solvo-thermal reaction, a solution containing a certain amount of precursors is placed into a Teflon liner and autoclaved at the desired temperature. The precursors can either be elemental precursor material or a corresponding salt or oxide; in most cases, hydrazine or $\mathrm{NaBH}_{4}$ is used as reducing agent for the preparation of $\mathrm{PbTe},{ }^{33-37} \mathrm{Bi}_{2} \mathrm{Te}_{3}$ (ref. 22 and 38-43) and $\mathrm{CoSb}_{3} \cdot{ }^{45,46}$ Templates and surfactants may also be used to control the growth. The obtained nanocrystals can be in the shape of nanoparticles, ${ }^{23,25,39,47}$ nanoplates, ${ }^{22,23,41,48}$ nanowires or nanocubes ${ }^{23,34,36,39,44,49,50}$ depending on the reaction conditions. The prepared nanopowders can be either single crystals with high phase and orientation purity, as shown in Fig. 1, or polycrystalline crystals, or partially amorphous nanocrystals. Normally, the dimensions of the prepared nanocrystals by the hydro/ 

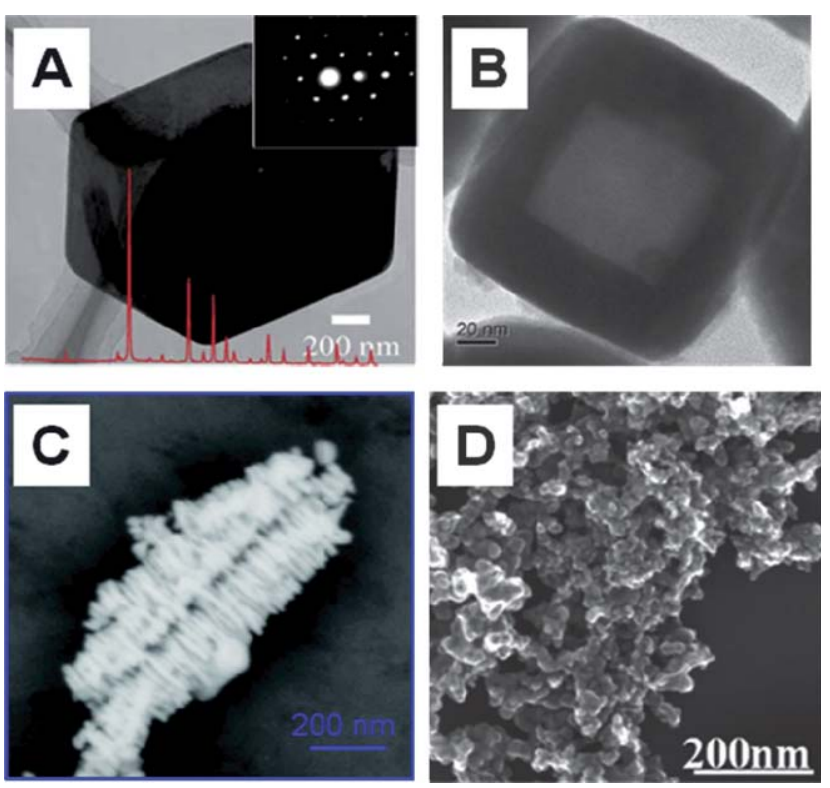

Fig. 1 (A) Electron micrographs and XRD pattern of hydrothermally prepared $\mathrm{Sb}_{2} \mathrm{Te}_{3}$ nanoplates (adapted from ref. 23 Copyright 2008 Wiley); (B) electron micrographs of solvothermally prepared $\mathrm{PbTe}$ nanobox (adapted from ref. 33 Copyright 2005 Wiley); (C) electron micrographs of $\mathrm{Bi}_{2} \mathrm{Te}_{3}$ nanostrings fabricated by a biomolecule-assisted hydrothermal approach (adapted from ref. 44 Copyright 2010 Am. Chem. Soc.); and (D) electron micrographs of hydrothermally prepared $\mathrm{CoSb}_{3}$ nanoparticles (adapted from ref. 47 Copyright 2008 American Institute of Physics).

solvo-thermal approaches are larger than $100 \mathrm{~nm}$, which is relatively large compared to the desired size to reduce lattice thermal conductivities by introducing more significant phonon scattering. However, it is shown that these nanopowders can still effectively reduce the lattice thermal conductivities in nanocomposites by co-compressing the hydrothermally prepared nanopowders with bulk micropowders. ${ }^{46,47,49,51,52}$ A recently biomolecule-assisted hydrothermally prepared $\mathrm{Bi}_{2} \mathrm{Te}_{3}$ (ref. 44) shows more than $50 \%$ lower thermal conductivity compared to the bulk material.

As mentioned above, bulk binary $\mathrm{PbTe}, \mathrm{Bi}_{2} \mathrm{Te}_{3}$ and $\mathrm{CoSb}_{3}$ have already been demonstrated not to be the best choice for thermoelectric applications. However, their corresponding alloys or solid state solutions including $\mathrm{Pb}_{1-x}\left(\mathrm{Sn}_{x}\right) \mathrm{Te}$, and $\mathrm{Bi}_{2-x}\left(\mathrm{Sb}_{x}\right)$ $\mathrm{Te}_{3-y}\left(\mathrm{Se}_{y}\right)$ show better thermoelectric performance. For example, $\mathrm{La}_{0.9} \mathrm{CoFe}_{3} \mathrm{Sb}_{12}-\mathrm{CoSb}_{3}$ (ref. 47) $\mathrm{AgPb}_{18} \mathrm{SbTe}_{20}$ (ref. 53 and 54) and $\mathrm{Bi}_{0.5} \mathrm{Sb}_{1.5} \mathrm{Te}_{3}$ (ref. 55) have recently been successfully synthesized by hydro/solvo-thermal approaches and were shown to have improvement in thermoelectric properties compared to pure $\mathrm{CoSb}_{3}, \mathrm{PbTe}$ and $\mathrm{Bi}_{2} \mathrm{Te}_{3}$ nanocrystals prepared by similar chemistry.

\section{Electrochemical deposition}

Electrochemical deposition is a process in which precursor ions are reduced to the product either from aqueous, organic or fusedsalt electrolytes. The reduction is often represented by

$$
\mathrm{M}^{z^{+}}+z \mathrm{e}^{-} \rightarrow \mathrm{M}
$$

and it can be accomplished either with an electrodeposition in which $z$ electrons are provided by an external power supply or with an electroless deposition in which a reducing agent serves as the electron source (no external power supply needed). In both cases the deposition is a reaction of charged particles at the interface between a solid metal electrode and a liquid solution. The two types of charged particles, namely the metal ions and the electrons, are able to cross the interface. ${ }^{56}$

Electrochemical deposition has been used widely in thin film fabrication for a long time due to its environmental friendliness and ease of scalability. Furthermore, electrochemical deposition reactions can be used to prepare IV-VI and V-VI chalcogenides at ambient temperature and pressure without using highly active reducing or oxidizing agents. Compared to hydro/solvo-thermal approaches, in which highly reactive agents, high temperature, and high pressure are adopted, electrochemical deposition has the advantage of requiring only mild redox reaction conditions that is controllable by deposition potential. However, it is difficult to fabricate nanostructures by regular electrochemical deposition without using any template. The first reported $\mathrm{Bi}_{2} \mathrm{Te}_{3}$ nanowire with the (110) orientation, high density and high crystallinity was electrochemically deposited by using an anodized aluminium oxide (AAO) template. ${ }^{24}$ This report provided three necessities for the electrochemical deposition of $\mathrm{Bi}_{2} \mathrm{Te}_{3}$ or PbTe nanowires: (1) acidic precursor solution to stabilize the AAO template during electrochemical deposition; (2) static potential deposition to help increase the phase purity of the products; and (3) the AAO template itself. The deposition of $\mathrm{Bi}_{2} \mathrm{Te}_{3}$ was further optimized in morphology, structure and composition and reported in a few following reports. ${ }^{16,57-63}$ Inspired by the electrochemical deposition of $\mathrm{Bi}_{2} \mathrm{Te}_{3}$ nanowires, the electrochemical deposition of PbTe was also reported and optimized. The more complicated and more promising $\mathrm{Bi}_{2-x} \mathrm{Sb}_{x} \mathrm{Te}_{3}$ (ref. 64) and $\mathrm{Bi}_{2} \mathrm{Te}_{3-y} \mathrm{Se}_{y}{ }^{65}$ nanowires, shown in Fig. 2, were soon made using a similar strategy. Unlike other reported thermoelectric single crystal nanowires prepared by other methods, which have been investigated by Peidong Yang and reviewed elsewhere, ${ }^{15,17,66}$ the regular electrochemically deposited nanowires are polycrystalline rather than single crystals.
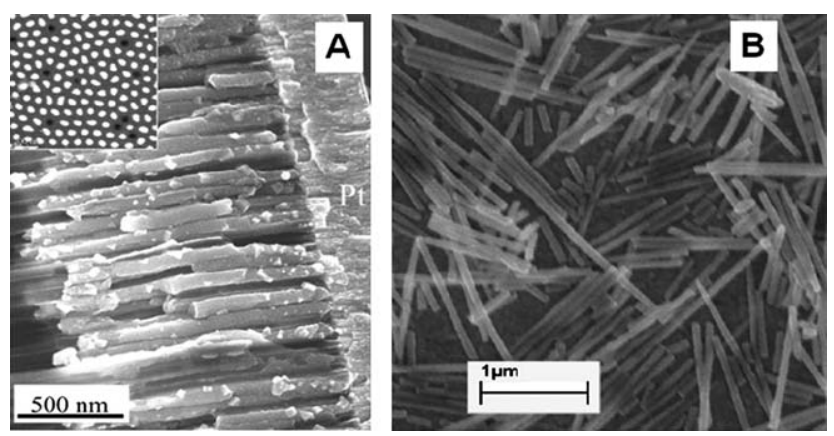

Fig. 2 (A) SEM of electrochemically deposited $50 \mathrm{~nm} \mathrm{Bi}_{2} \mathrm{Te}_{3-y} \mathrm{Se}_{y}$ nanowire arrays (inset is the top view) (adapted from ref. 65 Copyright 2003 Am. Chem. Soc.) and (B) microstructure of the superlattice BiSbTe nanowires after removal of the polycarbonate template (adapted from ref. 67 Copyright 2007 Wiley). 
Pulse deposition ${ }^{68}$ was developed for the preparation of high quality single crystal $\mathrm{PbTe}$ and $\mathrm{Bi}_{2} \mathrm{Te}_{3}$ nanowires. ${ }^{16,58}$ The pulse deposition techniques have even been developed toward the preparation of heterostructures and hollow nanowires based on PbTe- and $\mathrm{Bi}_{2} \mathrm{Te}_{3}$-type materials, which have been extensively studied by the Xiaoguang $\mathrm{Li}$ group and was also recently reviewed. ${ }^{15,16}$

The use of AAO templates helps the control of morphology of these thermoelectric nanowires. However, it also severely limits the scalability of electrochemical deposition. Different strategies have been developed to overcome the limitations of templates. One strategy is to modify the reaction solution: nanostructured $\mathrm{Bi}_{2-x} \mathrm{Sb}_{x} \mathrm{Te}_{3}$ films have been prepared by electrochemical deposition without the use of a template. The morphology of the reported nanostructured $\mathrm{Bi}_{2-x} \mathrm{Sb}_{x} \mathrm{Te}_{3}$ thin films was controlled by using ethylene glycol in the aqueous electrolyte. ${ }^{58}$ Another strategy is to combine sonochemistry and electrochemical deposition as discussed in the following section.

Besides electrochemical deposition, chemical bath deposition $^{69-73}$ can also effectively fabricate high quality nanostructured semiconductor thin films for various applications including thermoelectrics. In a typical chemical bath deposition, precursors dissolved in the same solution react to produce a solid material, often in the form of a film, onto a substrate that is exposed to the solution over the course of seconds to minutes. The nanostructured thermoelectric $\mathrm{Bi}_{2} \mathrm{Se}_{3}$ (ref. 74) and $\mathrm{PbSe}^{75}$ films, as shown in Fig. 3, were successfully prepared by chemical bath deposition, and their thermoelectric properties showed comparable power factors to the corresponding bulk materials. The thermoelectric properties of nanostructured $\mathrm{PbSe}$ thin films can also be modified through anisotropic growth by changing the reaction condition. ${ }^{75}$ However, the chemical bath deposition can currently only fabricate $\mathrm{PbSe}, \mathrm{Bi}_{2} \mathrm{Se}_{3}$ and $\mathrm{Sb}_{2} \mathrm{Se}_{3}$ while the chemical bath deposition of other thermoelectric materials, such as $\mathrm{PbTe}, \mathrm{Bi}_{2} \mathrm{Te}_{3}$ and $\mathrm{Sb}_{2} \mathrm{Te}_{3}$, is still a challenge.

\section{Sonochemical synthesis}

In sonochemical reactions, the compression of the bubbles during cavitation generates short-lived localized hot-spots, which have temperatures of several thousand Kelvin, pressures of about $1000 \mathrm{~atm}$, and heating and cooling rates of above $10^{10} \mathrm{~K}$ $\mathrm{s}^{-1}$. Extreme physical and chemical conditions have been applied in the synthesis of nanocrystals including the thermoelectric nanoparticles $\mathrm{PbE}$ and $\mathrm{Bi}_{2} \mathrm{E}_{3}(\mathrm{E}=\mathrm{S}, \mathrm{Se}, \mathrm{Te}){ }^{25,76-79}$ The sonochemical approach can not only produce highly crystalline small nanocrystals, but also heterostructured nanowires without the

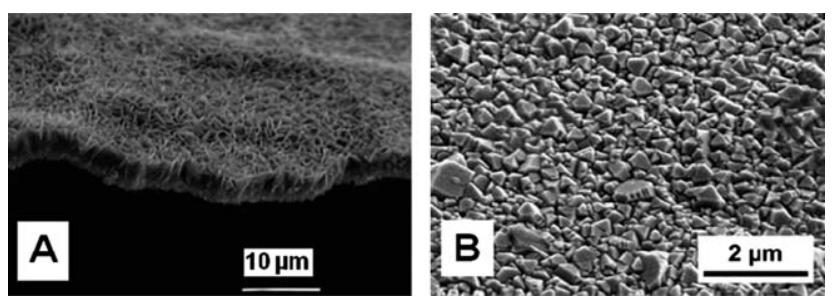

Fig. 3 SEM of chemical bath deposited thermoelectric films: (A) $\mathrm{Bi}_{2} \mathrm{Se}_{3}$ (adapted from ref. 74 Copyright 2006 Wiley) and (B) PbSe (adapted from ref. 75 Copyright 2010 RSC). need for a template. An example of $\mathrm{Bi}_{2} \mathrm{Se}_{3}$ heterostructured nanowires prepared by the sonochemical method is shown in Fig. 4A.

In the regular sonochemical preparation, it is easy to prepare IV-VI and V-VI chalcogenide nanocrystals such as $\mathrm{PbE}$ or $\mathrm{Bi}_{2} \mathrm{E}_{3}$, when $\mathrm{E}=\mathrm{S}$ or Se. ${ }^{26,74,77,79,80}$ However, it is much more difficult to synthesize them when $\mathrm{E}$ is Te. Electrochemical deposition has demonstrated the successful preparation of tellurides by adjusting the deposition potential, but their preparation of fine nanostructures still requires the assistance of a template. Sonoelectrochemistry, the combination of sonochemistry and electrochemical deposition, succeeded in the preparation of thermoelectric telluride nanocrystals and nanowires. Anisotropic PbTe nanocrystals have been successfully prepared as shown in Fig. 4B. ${ }^{27}$

Although sonochemistry is a clean and facile method to prepare thermoelectric nanomaterials, the reaction outcomes are very sensitive to the frequency and intensity of ultrasound, which makes it inconvenient for bulk production. Therefore, there are to date very few reports of thermoelectric properties on sonochemically prepared thermoelectric nanomaterials. ${ }^{76}$

\section{Ligand-based synthesis}

Ligand-based synthesis involves the use of organic ligands such as the most commonly used TOPO (trioctylphosphine oxide) to control the shape and orientation of the final nanocrystals. It is one of the most important methods for preparing shapecontrolled, monodispersed colloidal nanocrystals. ${ }^{18,81}$ In ligand-based synthesis, the growth kinetics and orientation of nanocrystals can be adjusted by the choice of ligands, reaction temperature and time. Numerous high quality semiconductor quantum dots and binary and ternary nanocrystals have been successfully synthesized through this approach. The first reported colloidal $\mathrm{Bi}_{2} \mathrm{Te}_{3}$ nanocrystals synthesized by ligand-based synthesis ${ }^{29}$ show a much smaller size and a narrower size distribution than those prepared by hydro/solvo-thermal and electrochemical deposition. Later, other popular thermoelectric nanomaterials such as $\mathrm{Bi}, \mathrm{PbSe}, \mathrm{PbTe}(\mathrm{Se}), \mathrm{Sb}_{2} \mathrm{Te}_{3}$, and $\mathrm{Bi}_{2-x} \mathrm{Sb}_{x} \mathrm{Te}_{3}$ were synthesized successfully by ligand-based

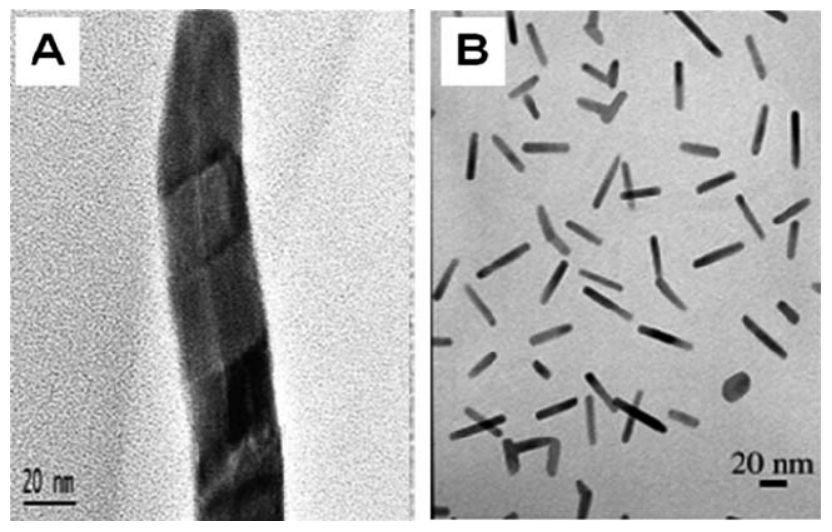

Fig. 4 (A) TEM of sonochemically prepared heterostructured $\mathrm{Bi}_{2} \mathrm{Se}_{3}$ nanowires (adapted from ref. 25 Copyright 2004 Am. Chem. Soc.) and (B) sonoelectrochemically prepared PbTe nanorods (adapted from ref. 27 Copyright 2005 Wiley). 
synthesis. ${ }^{17,30,82-98}$ Similar to the $\mathrm{Bi}_{2} \mathrm{Te}_{3}$, these nanomaterials, as shown in Fig. 5, also show smaller sizes and narrower size distributions than those prepared by other approaches.

In the preparation of $\mathrm{PbSe}(\mathrm{Te})$ nanocrystals by ligand-based synthesis, the $\mathrm{Se}(\mathrm{Te})$ precursor is $\mathrm{TOPSe}(\mathrm{Te})$, which is also widely used in the preparation of chalcogenide type quantum dots, while the precursor for $\mathrm{Pb}$ is usually $\mathrm{PbO}$, which can easily form a lead oleate solution by reacting with oleic acid at mild temperatures under the protection of inert gas. Monodispersed $\mathrm{PbSe}$ and $\mathrm{PbTe}$ nanocrystals with different sizes and shapes have been successfully synthesized for thermoelectric applications. ${ }^{84,85,89,91,93}$ However, there is no such a convenient $\mathrm{Bi}$ precursor for the preparation of $\mathrm{Bi}_{2} \mathrm{Se}(\mathrm{Te})_{3}$ nanocrystals because bismuth oleate is difficult to be prepared by reacting $\mathrm{Bi}_{2} \mathrm{O}_{3}$ with oleic acid at mild temperatures. This difference makes the number of reports for the synthesis of $\mathrm{Bi}_{2}(\mathrm{Se}, \mathrm{Te})_{3} \mathrm{NCs}$ comparatively fewer than that of $\mathrm{Pb}(\mathrm{Se}, \mathrm{Te}){ }^{24,44,58,60,63,65}$

In most cases, the $\mathrm{Se}$ or Te precursors are either $\left(\mathrm{Me}_{3} \mathrm{Si}_{2} \mathrm{Te}^{29}\right.$ or TOPSe(Te), which are widely adopted in ligand-based synthesis of chalcogenide nanocrystals. All these $\mathrm{Se}(\mathrm{Te})$ precursors are toxic and expensive, which prevents the widespread production of chalcogenide nanocrystals. In very recent reports, the elements Se and Te could be directly used as the precursors for the preparation of chalcogenide nanocrystals when much cheaper reagents, such as hydrazine ${ }^{90}$ and sodium borohydride, were used. ${ }^{93}$ This progress provides environmentally friendlier precursors for future ligand-based synthesis.

Uniform and high quality $\mathrm{PbSe}(\mathrm{Te})$ films or nanowires, as shown in Fig. 6A and B, have been extensively studied by Murray's ${ }^{89,95-97}$ and Yang' ${ }^{84,85}$ groups for their thermoelectric
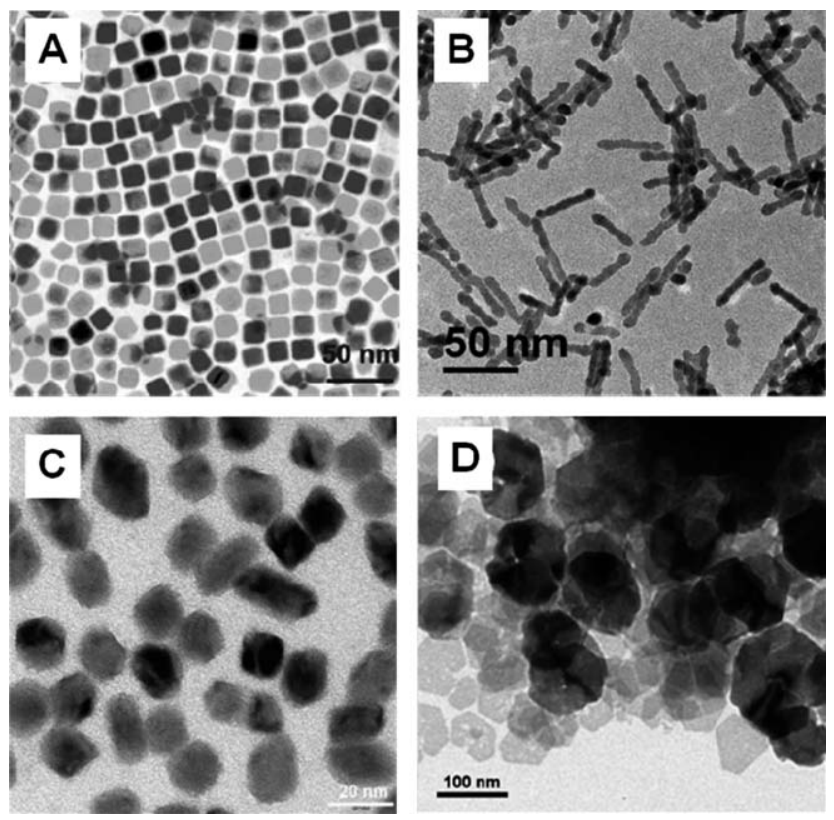

Fig. 5 TEM images of ligand-based synthesized nanocrystals: (A) PbTe nanocubes (adapted from ref. 96 Copyright 2004 Am. Chem. Soc.); (B) $\mathrm{PbSe}$ nanorods (adapted from ref. 97 Copyright $2010 \mathrm{Am}$. Chem. Soc.); (C) $\mathrm{Bi}_{2} \mathrm{Te}_{3}$ nanoparticles (adapted from ref. 88 Copyright 2009 Wiley); and (D) $\mathrm{Bi}_{2-x} \mathrm{Sb}_{x} \mathrm{Te}_{3}$ nanoplates (adapted from ref. 99 Copyright 2010 Am. Chem. Soc.).
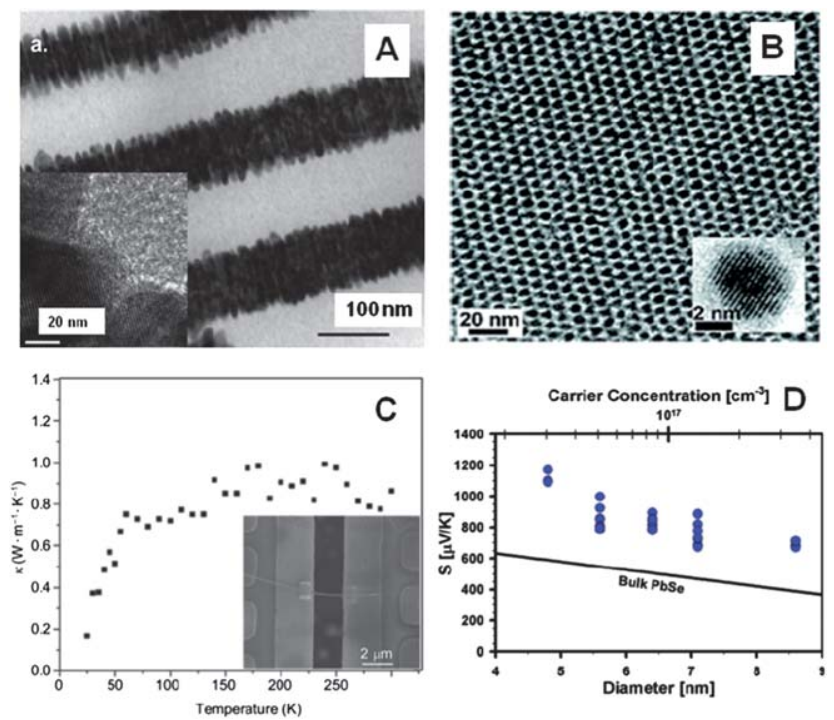

Fig. 6 (A) TEM image of PbSe nanowires (adapted from ref. 84 Copyright 2009 Am. Chem. Soc.); (B) TEM image of PbTe nanocrystal superlattices (adapted from ref. 95 Copyright 2006 Am. Chem. Soc.); (C) thermal conductivity of a single $\mathrm{PbSe}$ nanowire as a function of the temperature. Inset: SEM image of the measured device (adapted from ref. 85 Copyright 2009 Springer). (D) The thermopower curve of different sized $\mathrm{PbSe}$ nanocrystals with different carrier concentrations compared to bulk PbSe (adapted from ref. 91 Copyright 2009 Springer).

properties. In these nanostructured $\mathrm{PbSe}$ nanowires, a two-fold lower thermal conductivity compared to the bulk material was observed. ${ }^{85}$ The temperature dependent thermal conductivity curve shown in Fig. 6C exhibits a different temperature dependence from the bulk material due to phonon boundary scattering.

Other than the significant decrease of thermal conductivities, the PbSe nanocrystals also exhibited an additional property: increasing thermopower $(S)$ through size quantum effects. The promise of higher ZT values in nanomaterials compared to the bulk material is mainly based on two aspects. One is the decrease of thermal conductivity $(\kappa)$ due to nanoscale grain boundaries, and the other is the enhancement of the thermopower $(S)$ arising from the electronic quantum size effects. ${ }^{91}$ The decrease of thermal conductivity has been reported and was realized with nanomaterials prepared by both bottom-up and top-down techniques. There is a physical limitation for the reduction of thermal conductivities, however, and so far there is not much room left to further increase ZT values just by reducing the thermal conductivities. As a consequence, the enhancement of thermopower $(S)$ is a promising strategy and a realistic route for further increasing ZT values. Nevertheless, to date, enhancement of the thermopower $S$ by quantum size effects is rarely reported. One reason may be due to the fact that increasing of thermopower $S$ only takes place when the size of these thermoelectric nanocrystals is much less than their Bohr radius, while most ball milling techniques and regular solution-based approaches cannot efficiently prepare such small nanocrystals. In ref. 91 the thermopower of such $\mathrm{PbSe}$ nanocrystals shows more than 30\% enhancement compared to bulk materials with nearly identical carrier concentrations (see Fig. 6D). The Bohr radius of PbSe is 
around $50 \mathrm{~nm}$, while the size of the reported thermopowerenhanced PbSe nanocrystals is less than $10 \mathrm{~nm}$, which can only be realized with ligand-based synthesis. It is believed that there is much potential to be explored in enhancing the thermopower $S$ through quantum effects by using ligand-based synthesis.

\section{Progress and challenges in thermoelectric materials processing}

The above mentioned solution chemistry approaches have been used to prepare many of today's thermoelectric nanomaterials with various sizes and shapes. Based on the optimistic projection that nanostructures could increase the thermoelectric performance, these thermoelectric nanomaterials are expected to exhibit better ZT values than the bulk ones, which has been demonstrated in thermoelectric nanomaterials prepared by topdown methods. ${ }^{13}$ However, as to the nanomaterials prepared by solution chemistry approaches, the reality in the early beginning was that ZT values were not improved at all; rather, they were much lower than those for the bulk materials. ${ }^{13}$ As pointed out by Kanatzidis et al., ${ }^{20}$ a successful approach for thermoelectric development requires the combination of theoretical guidance, chemical synthesis, material processing and performance measurement. We propose that the low ZT values in early reports on thermoelectric nanomaterials, prepared by solution chemistry approaches, were to some extent due to a lack of a cross-disciplinary approach. In particular, the materials processing and performance analysis techniques were initially rather limited. A widely adopted material processing technique to improve materials density and electrical conductivity was cold pressing, ${ }^{\mathbf{8 2 , 1 0 0 , 1 0 1}}$ which had been demonstrated as an unsuccessful technique in the study of bulk materials decades ago. ${ }^{102,103}$ Because of the complexity of thermal conductivity measurements, the decrease of thermal conductivity was even less of a focus. Soon, hydro/ solvo-thermal synthesis became the mainly adopted method for most thermoelectric nanomaterials, in part due to the simplicity of the preparation method. Eventually, the thermal conductivities of such materials could also be lowered compared to bulk materials. This has been thoroughly investigated by the Tritt group. ${ }^{35,47,51,52,104}$

Once the importance of a crossdisciplinary approach to thermoelectric materials synthesis has been recognized, the performance of the thermoelectric nanomaterials prepared by solution chemistry improved substantially. As a result the efficiencies became comparable with the optimized bulk values. For example, the preparation and shape control of electrochemically deposited $\mathrm{PbTe}$ or $\mathrm{Bi}_{2} \mathrm{Te}_{3}$ nanostructured thin films and nanowires has been well investigated, ${ }^{15,16,24,27,57-65,67,68,74,105-113}$ but most of the electrochemically deposited nanowires were poor in thermopower performances, especially their lower electrical conductivities, compared to the regular bulk ones. In a recent report, ${ }^{112}$ the $\mathrm{Bi}_{2} \mathrm{Te}_{3}$ nanowires were prepared by a typical electrochemical deposition approach but with careful post-synthesis treatment and were fabricated as a thermoelectric device. The ZT value reached 0.9 at $350 \mathrm{~K}$ due to the significant reduction of thermal conductivity. It is believed that the $\mathrm{ZT}$ value of these $\mathrm{Bi}_{2} \mathrm{Te}_{3}$ nanowires can be even higher once the carrier concentration, and with that the thermopower, can be further optimized.
It is worth pointing out the progress and challenges of thermoelectric nanomaterials prepared by ligand-based synthesis, which shows progress toward higher ZT values as a good example of an interdisciplinary approach. For example, in 2009, the first report of a detailed thermoelectric analysis of colloidal $\mathrm{Bi}_{2} \mathrm{Te}_{3}$ nanocrystals was published. In this report, the obvious advantage of lowering lattice thermal conductivity in colloidal $\mathrm{Bi}_{2} \mathrm{Te}_{3}$ nanocrystals was demonstrated with a more than $50 \%$ decrease of lattice thermal conductivities compared to bulk $\mathrm{Bi}_{2} \mathrm{Te}_{3} .{ }^{82}$ However, the resulting $\mathrm{ZT}$ value in this report was still very low, around 0.03 . This low performance was mainly due to the poor thermopower and electrical conductivity, the latter of which is a persistent challenge for bottom-up approaches. The reason behind this is that the organic solvent and organic surfactant used in ligand-based synthesis deteriorate the electrical properties of the $\mathrm{Bi}_{2} \mathrm{Te}_{3}$ nanocrystals. In that report, the ligand capped colloidal $\mathrm{Bi}_{2} \mathrm{Te}_{3}$ nanocrystals show up to 5 orders of magnitude lower electrical conductivity compared to the bulk material. Although the electrical conductivities can be improved once the capping ligand is removed by annealing, their values are still an order of magnitude lower than that of state-of-the-art values in bulk thermoelectrics. Following this pioneering work, two other publications demonstrated that both argon protected annealing $^{101}$ and spark plasma sintering ${ }^{88}$ can significantly increase the electrical conductivity of these colloidal $\mathrm{Bi}_{2} \mathrm{Te}_{3}$ nanocrystals by a factor of ten. The resulting ZT values were improved to around 0.1 (ref. 101) and $0.2{ }^{88}$ respectively. The evolution of the thermoelectric properties for $\mathrm{Bi}_{2} \mathrm{Te}_{3}$ nanocrystals in these three reports is listed in Table 1. The significant progress in such a short time resulted likely due to increased efforts across the disciplines.

From Table 1, one finds that ligand-based synthesized nanocrystals still present lower thermoelectric performance than bulk materials, even though advanced material processing techniques, like spark plasma sintering, were used. The reason for this is the unoptimized carrier concentration, which is a major obstacle for nanocrystals prepared by solution chemistry approaches. Carrier concentration is one of the most important parameters in determining and optimizing the ZT value in either bulk or nanosized thermoelectric materials. In solid state synthesis on the bulk scale, chemistry has mastered the skills and techniques to achieve the best thermoelectrics by adjusting the carrier concentration in bulk materials through doping. The failure of solution chemistry to carefully design and adjust the reaction product in terms of carrier concentration is in stark contrast to the good level of size and morphology control that is being exercised in nanoparticles synthesis. To adjust carrier concentrations in nanocrystals prepared by solution chemistry, two strategies have been reported. The first one is to improve the $\mathrm{PbTe} \mathrm{NCs}$ with lower carrier concentration by assembling with $\mathrm{Ag}_{2} \mathrm{Te}$ and $\mathrm{PtTe}_{2} \mathrm{NCs}^{89,92}$ and the resulting carrier concentration and electrical conductivity were modified by several orders of magnitude as shown in Fig. 7.

The second strategy is to adjust the carrier concentration by intentionally introducing defects into the nanocrystal. In our recent report, it was demonstrated that the thermoelectric performance of colloidal $\mathrm{Bi}_{2} \mathrm{Te}_{3}$ nanocrystals can be improved by adjusting carrier concentrations ${ }^{\mathbf{1 0 0}}$ through partial $\mathrm{Sb} / \mathrm{Bi}$ substitution as shown in Fig. 8, and the ZT value of colloidal $\mathrm{Bi}_{2} \mathrm{Te}_{3}$ 
Table 1 Thermoelectric improvement in three $\mathrm{Bi}_{2} \mathrm{Te}_{3}$ nanocrystal examples. All values were reported at $300 \mathrm{~K}$ except for the thermal conductivities, which were data at $200 \mathrm{~K}$ due to the radiation effects at higher temperatures

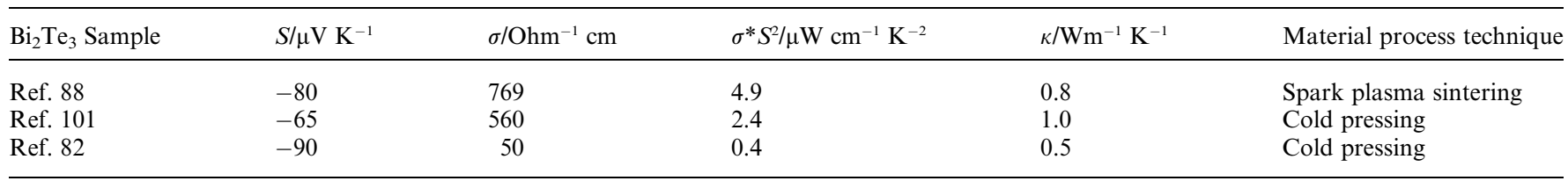

nanocrystals could be improved to $\sim 0.3$ even though they were only processed by cold pressing. Months later, similar colloidal $\mathrm{Bi}_{2} \mathrm{Te}_{3}$ based nanocrystals prepared by similar methods exhibited a ZT value of 0.9 when processed with chemically more advanced hydrazine treatment and spark plasma sintering techniques. ${ }^{99}$

The significant progress in the field of thermoelectric nanocrystals where $\mathrm{Bi}_{2} \mathrm{Te}_{3}$ nanocrystals improved their $\mathrm{ZT}$ values from 0.03 to 0.9 within a year demonstrates the large potential of solution chemistry for thermoelectric nanomaterials. It is evident that high quality thermoelectric nanostructures will be synthesized, processed and characterized on a much broader scope once the necessary aspects of chemistry, material science and physics will be further integrated. In addition, one may consider that most precursors used in these recent works where high $\mathrm{ZT}$ values of $\mathrm{Bi}_{2} \mathrm{Te}_{3}$ nanowire ${ }^{112}$ and $\mathrm{Bi}_{2} \mathrm{Te}_{3}$ nanocrystals ${ }^{99}$ are reported are of regular chemical purity of $99 \%$, while all the precursors in regular solid state synthesis of thermoelectric bulk materials need to be elemental powders of up to $99.99 \%$ or higher purity. This indicates the possibility of large scale production of high performance thermoelectric nanomaterials at significantly lower cost through solution phase chemistry.

\section{New routes in solution chemistry}

As discussed above, solution chemistry is still largely focusing on synthesizing high quality nanomaterials with novel approaches different from top-down methods. However, the target materials are still based on traditional high performance thermoelectric materials. On the other hand, very recent work reported fundamentally novel directions of solution chemistry approaches towards thermoelectrics. Talapin et al. developed metal chalcogenide complexes (MCCs) functioning as an electronic glue to modify the colloidal nanocrystals such as $\mathrm{PbTe}$ and $\mathrm{Bi}_{2} \mathrm{~S}_{3}{ }^{83}$ This solution chemistry approach does not only help preserve the nanostructures and the high electrical conductivity but also adjust the composition of the colloidal thermoelectric nanocrystals. For example, it can adjust $\mathrm{Bi}_{2} \mathrm{Te}_{3}$ to $(\mathrm{BiSb})_{2} \mathrm{Te}_{3}$ or $(\mathrm{BiSb})_{2}(\mathrm{SeTe})_{3}$. Fig. 9 shows the conservation of nanostructure colloidal thermoelectric nanocrystals by using $\mathrm{Sb}_{2} \mathrm{Te}_{3}$ as MCCs, after $300{ }^{\circ} \mathrm{C}$ annealing. ${ }^{83}$

Recently, organic and inorganic hybrid structures improved a lot in the TE performance. In Chen et al.'s work, single wall carbon nanotubes/polyaniline hybrid nanocomposites show two orders of magnitude higher power factor compared to pure polyaniline. ${ }^{114}$ Segalman et al. prepared poly(3,4-ethylenedioxythiophene):poly(styrenesulfonate) and $\mathrm{Te}$ nanorods hybrid structures using water processable techniques and the measured ZT value was around 0.1 , which is a historically high value for organic thermoelectric materials. The morphologies of these two reported organic-inorganic hybrid materials are shown in Fig. 10.

\section{Summary and outlook}

During the last decade, numerous thermoelectric nanomaterials have been successfully synthesized by solution chemistry approaches including hydro/solvothermal, electrochemical, and ligand-based synthesis. These approaches have demonstrated their advantages in achieving small size and narrow size distributions and morphological control compared to top-down approaches. Initially, solution chemistry focused more on the synthesis rather than the adjustment of thermoelectric properties, which might be one of the reasons for the low performance of the early products. The achievements of lower thermal conductivities in early reports of solution synthesized nanomaterials had been counteracted by their low power factors due to the low electrical conductivities and thermopower. Organic surfactant residues and inappropriate carrier concentrations have been accounted for the measured low power factors. Recently, post-synthesis treatments such as hydrazine treatment and inert gas protection
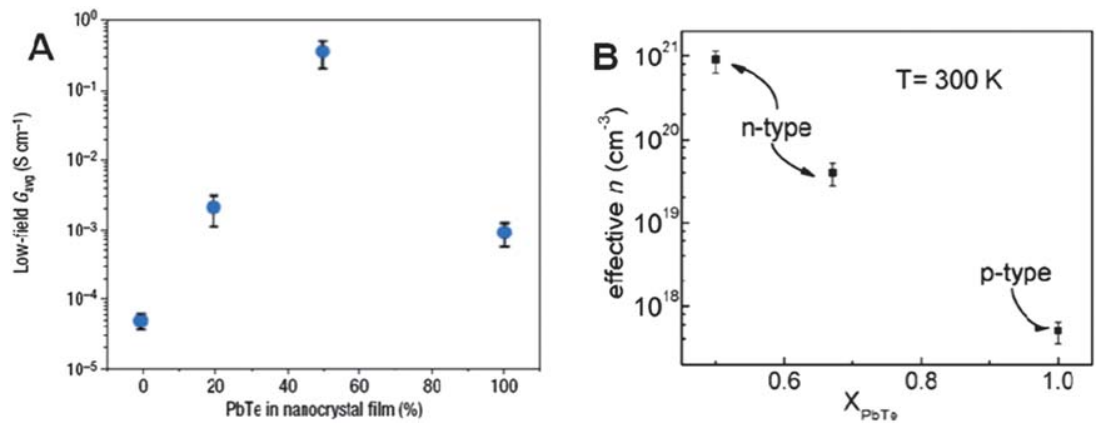

Fig. 7 (A) Comparison of low-field conductance of different PbTe : $\mathrm{Ag}_{2}$ Te ratio superlattices (adapted from ref. 89 Copyright 2007 Nature). (B) Charge carrier concentration of three types of samples with different PbTe contents (adapted from ref. 92 Copyright 2009 Wiley). 


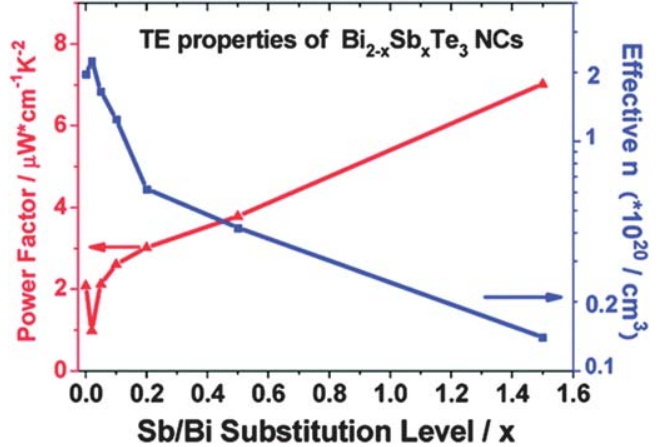

Fig. 8 The carrier concentration and power factor of chemically synthesized $\mathrm{Bi}_{2} \mathrm{Te}_{3}$-based nanocrystals (NCs) with different $\mathrm{Sb} / \mathrm{Bi}$ substitution levels in ternary $\mathrm{Bi}_{2-x} \mathrm{Sb}_{x} \mathrm{Te}_{3} \mathrm{NCs}(x=0.02,0.05,0.10,0.20$, 0.50 , and 1.50) (adapted from ref. 100 Copyright $2010 \mathrm{Am}$. Chem. Soc.)

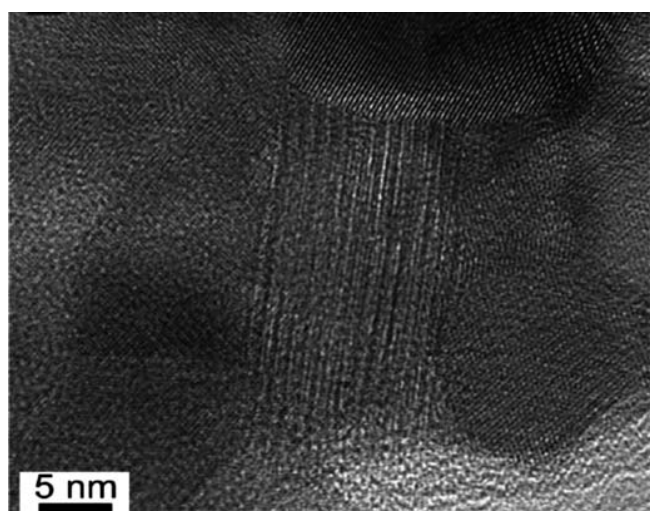

Fig. 9 TEM image of nanostructured $\mathrm{PbTe} /(\mathrm{Bi}, \mathrm{Sb})_{2} \mathrm{Te}_{3}$ prepared by mixing $\mathrm{Sb}_{2} \mathrm{Te}_{3}-\mathrm{MCC}$ capped $\mathrm{PbTe} \mathrm{NCs}$ with $(\mathrm{Bi}, \mathrm{Sb})_{2} \mathrm{Te}_{3}$ nanocrystals and annealing at $300{ }^{\circ} \mathrm{C}$ (adapted from ref. 83 and 114 Copyright 2010 Am. Chem. Soc.).
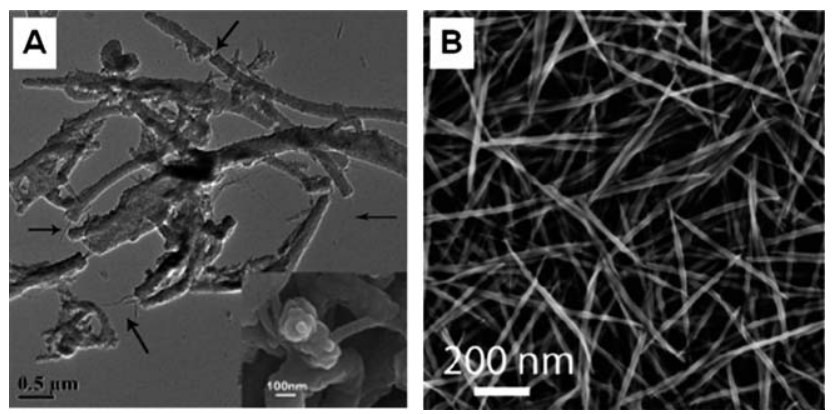

Fig. 10 (A) TEM images for SWNT/PANI composites with $25 \mathrm{wt} \%$ SWNT. Inset is the SEM top view of the nanocables (adapted from ref. 114 Copyright $2010 \mathrm{Am}$. Chem. Soc.). (B) SEM image of a drop-cast composite Te nanorod with PEDOT:PSS film (adapted from ref. 115 Copyright 2010 Am. Chem. Soc.).

annealing have been demonstrated as efficient approaches to remove the surfactant residues and reverse the surface oxidation. $^{82,88,99-101}$ These post-treated nanomaterials showed comparable electrical conductivities to state of art values in bulk materials. Attempts of optimizing charge carrier concentrations in solution synthesized thermoelectric nanomaterials have been realized by incorporating nanomaterials with different carrier concentrations or initially adjusting the carrier concentration by introducing dopands during the wet chemical synthesis. ${ }^{89,92,99,100}$ With the above mentioned developments and the help of additional materials processing, recent thermoelectric performances of solution chemistry based nanomaterials were reported to be improved to the point of being comparable with or even better than those of bulk materials. ${ }^{\mathbf{1 8 , 8 3}}$

Although great progress has been achieved in thermoelectric performance, there are still several immediate challenges for solution chemistry approaches toward preparing high-performance thermoelectric materials. The first and most urgent one is to obtain materials with ZT values higher than those of bulk materials and simultaneously of lower cost than bulk materials, because cost will dictate the future use of these materials and it is supposed to be one of the main advantages of solution-based synthesis. A second challenge is to develop novel thermoelectric materials beyond the typical $\mathrm{PbTe}$ - and $\mathrm{Bi}_{2} \mathrm{Te}_{3}$-type materials. It is a crucial advantage that solution chemistry can provide an enormous range of compositional flexibility to thermoelectric materials. To address these challenges, solution-based synthesis needs to focus on some practical issues. First, it is urgent to develop simple techniques for gram-scalable synthesis of thermoelectric nanomaterials, especially with less use of organic surfactants. Second, solution chemistry should develop more control over charge carrier concentrations during the synthesis and post-treatment, which would help to produce thermoelectric nanomaterials comparable to other advanced methods. Third, solution chemistry has to demonstrate its use to enhance thermopower besides lowering thermal conductivities. Enhanced thermopower is a new arena for achieving better thermoelectrics. An obvious task is to develop quantum-effect enhanced thermopower thermoelectric nanomaterials other than the already reported $\mathrm{PbSe}$ quantum dots. The fourth and maybe most intriguing tasks for solution chemistry is to develop other types of thermoelectric nanomaterials such as metal oxide and organic thermoelectric materials. Hydro/solvo-thermal and other solution chemistry approaches are believed to have the potential to prepare novel metal oxide nanomaterials for thermoelectric applications as they have demonstrated their capabilities in the preparation of different morphologies and compositions for metal oxide nanomaterials. Recent progress of hybrid organicinorganic thermoelectrics indicated that solution chemistry can play a unique role in these hybrid composition nanomaterials. ${ }^{14,115}$ It is believed by the authors that solution chemistry will demonstrate its capability in thermoelectrics synthesis with the proposed developments in the near future.

As recently pointed out by various experts in the thermoelectrics field, ${ }^{\mathbf{1 1 9}}$ there is still a very long way to go for large scale power generation via thermoelectric materials and we should not expect a revolutionary improvement in ZT values over a short period of time. Too much trust into the future development of solution-based nanochemistry may have caused an unjustified and exaggerated optimism at the beginning of this century, but this has been corrected during the past decade. ${ }^{20}$ Fortunately, scientists involved in the endeavor of developing improved thermoelectrics, increasingly tend to collaborate, explore, test and challenge each others' novel ideas and techniques since there is at this point not any single synthesis method that could be 
described as the perfect solution for improving ZT values. Therefore, we expect that the diversity in chemical approaches and techniques to enhance thermoelectric properties will lead to increasing energy conversion efficiencies.

\section{Acknowledgements}

C.B. acknowledges support from NSF (\#CHE-0239688), ACSPRF (\# 45359-AC10) and the Ohio Board of Regents, and J.S.D. acknowledges support from the Huntington and Codrington Foundations.

\section{References}

1 C. B. Vining, Nat. Mater., 2009, 8, 83-85.

2 C. B. Vining, Nature, 2001, 413, 577-578.

3 F. J. DiSalvo, Science, 1999, 285, 703-706.

4 G. S. Nolas, J. Sharp and H. J. Goldsmid, Thermoelectrics: Basic Principles and New Materials Developments, Springer, Berlin, Heidelberg, 2001.

5 G. S. Nolas, J. Poon and M. Kanatzidis, MRS Bull., 2006, 31, 199 205.

6 T. M. Tritt, Science, 1999, 283, 804-805.

7 T. M. Tritt and M. A. Subramanian, MRS Bull., 2006, 31, 188-194.

8 L. D. Hicks and M. S. Dresselhaus, Phys. Rev. B: Condens. Matter, 1993, 47, 12727-12731.

9 L. D. Hicks and M. S. Dresselhaus, Phys. Rev. B: Condens. Matter, 1993, 47, 16631-16634.

10 T. C. Harman, P. J. Taylor, M. P. Walsh and B. E. LaForge, Science, 2002, 297, 2229-2232.

11 R. Venkatasubramanian, E. Siivola, T. Colpitts and B. O’Quinn, Nature, 2001, 413, 597-602.

12 B. Poudel, Q. Hao, Y. Ma, Y. C. Lan, A. Minnich, B. Yu, X. Yan, D. Z. Wang, A. Muto, D. Vashaee, X. Y. Chen, J. M. Liu, M. S. Dresselhaus, G. Chen and Z. Ren, Science, 2008, 320, 634-638.

13 Y. C. Lan, A. J. Minnich, G. Chen and Z. F. Ren, Adv. Funct. Mater., 2010, 20, 357-376.

14 A. J. Minnich, M. S. Dresselhaus, Z. F. Ren and G. Chen, Energy Environ. Sci, 2009, 2, 466-479.

15 G. Q. Zhang, Q. X. Yu, W. Wang and X. G. Li, Adv. Mater., 2010, 22, 1959-1962.

16 F. Xiao, C. Hangarter, B. Yoo, Y. Rheem, K. H. Lee and N. V. Myung, Electrochim. Acta, 2008, 53, 8103-8117.

17 A. I. Hochbaum and P. D. Yang, Chem. Rev., 2010, 110, 527-546.

18 D. V. Talapin, J. S. Lee, M. V. Kovalenko and E. V. Shevchenko, Chem. Rev., 2010, 110, 389-458.

19 J. R. Sootsman, D. Y. Chung and M. G. Kanatzidis, Angew. Chem., Int. Ed., 2009, 48, 8616-8639.

20 M. G. Kanatzidis, Chem. Mater., 2010, 22, 648-659.

21 H. Liu, J. Y. Wang, X. B. Hu, L. X. Li, F. Gu, S. R. Zhao, M. Y. Gu, R. I. Boughton and M. H. Jiang, J. Alloys Compd., 2002, 334, 313316.

22 W. Z. Wang, B. Poudel, J. Yang, D. Z. Wang and Z. F. Ren, J. Am. Chem. Soc., 2005, 127, 13792-13793.

23 W. D. Shi, L. Zhou, S. Y. Song, J. H. Yang and H. J. Zhang, Adv. Mater., 2008, 20, 1892-1897.

24 A. L. Prieto, M. S. Sander, M. Martin-Gonzalez, R. Gronsky, T. Sands and A. M. Stacy, J. Am. Chem. Soc., 2001, 123, 7160-7161

25 X. F. Qiu, C. Burda, R. L. Fu, L. Pu, H. Y. Chen and J. J. Zhu, J. Am. Chem. Soc., 2004, 126, 16276-16277.

26 A. Gedanken, Ultrason. Sonochem., 2004, 11, 47-55.

27 X. F. Qiu, Y. B. Lou, A. C. S. Samia, A. Devadoss, J. D. Burgess, S. Dayal and C. Burda, Angew. Chem., Int. Ed., 2005, 44, 5855-5857.

28 Y. X. Zhao, H. C. Pan, Y. B. Lou, X. F. Qiu, J. J. Zhu and C. Burda, J. Am. Chem. Soc., 2009, 131, 4253-4261.

29 E. E. Foos, R. M. Stroud and A. D. Berry, Nano Lett., 2001, 1, 693 695.

30 P. Christian and P. O'Brien, J. Mater. Chem., 2005, 15, 3021-3025.

31 M. S. Toprak, C. Stiewe, D. Platzek, S. Williams, L. Bertini, E. C. Muller, C. Gatti, Y. Zhang, M. Rowe and M. Muhammed, Adv. Funct. Mater., 2004, 14, 1189-1196.
32 M. S. Dresselhaus, G. Chen, M. Y. Tang, R. G. Yang, H. Lee, D. Z. Wang, Z. F. Ren, J. P. Fleurial and P. Gogna, Adv. Mater., 2007, 19, 1043-1053.

33 W. Z. Wang, B. Poudel, D. Z. Wang and Z. F. Ren, Adv. Mater., 2005, 17, 2110-2114.

34 L. Z. Zhang, J. C. Yu, M. S. Mo, L. Wu, K. W. Kwong and Q. Li, Small, 2005, 1, 349-354.

$35 \mathrm{X}$. Ji, B. Zhang, T. M. Tritt, J. W. Kolis and A. Kumbhar, J. Electron. Mater., 2007, 36, 721-726.

36 G. Tai, B. Zhou and W. L. Guo, J. Phys. Chem. C, 2008, 112, 11314 11318.

37 G. A. Tai, W. L. Guo and Z. H. Zhang, Cryst. Growth Des., 2008, 8, 2906-2911.

38 H. T. Zhang, X. G. Luo, C. H. Wang, Y. M. Xiong, S. Y. Li and X. H. Chen, J. Cryst. Growth, 2004, 265, 558-562.

39 X. B. Zhao, X. H. Ji, Y. H. Zhang and B. H. Lu, J. Alloys Compd., 2004, 368, 349-352.

40 H. L. Ni, X. B. Zhao, T. J. Zhu, X. H. Ji and J. P. Tu, J. Alloys Compd., 2005, 397, 317-321.

41 B. Zhou, Y. Ji, Y. F. Yang, X. H. Li and J. H. Zhu, Cryst. Growth Des., 2008, 8, 4394-4397.

42 Q. Zhao and Y. G. Wang, J. Alloys Compd., 2010, 497, 57-61.

43 Y. Deng, C. W. Nan, G. D. Wei, L. Guo and Y. H. Lin, Chem. Phys. Lett., 2003, 374, 410-415.

44 J. L. Mi, N. Lock, T. Sun, M. Christensen, M. Sondergaard, P. Hald, H. H. Hng, J. Ma and B. B. Iversen, ACS Nano, 2010, 4, 25232530.

45 X. B. Zhao, S. H. Yang, Y. Q. Cao, J. L. Mi, Q. Zhang and T. J. Zhu, J. Electron. Mater., 2009, 38, 1017-1024.

46 J. L. Mi, X. B. Zhao, T. J. Zhu and J. P. Tu, Appl. Phys. Lett., 2007, 91, 172116

47 P. N. Alboni, X. Ji, J. He, N. Gothard and T. M. Tritt, J. Appl. Phys., 2008, 103, 113707.

48 T. Wang, R. Mehta, C. Karthik, P. G. Ganesan, B. Singh, W. Jiang, N. Ravishankar, T. Borca-Tasciuc and G. Ramanath, J. Phys. Chem. C, 2010, 114, 1796-1799.

49 X. B. Zhao, X. H. Ji, Y. H. Zhang, T. J. Zhu, J. P. Tu and X. B. Zhang, Appl. Phys. Lett., 2005, 86, 062111.

50 Q. F. Han, J. Chen, X. J. Yang, L. Lu and X. Wang, J. Phys. Chem. C, 2007, 111, 14072-14077.

51 X. H. Ji, J. He, Z. Su, N. Gothard and T. M. Tritt, J. Appl. Phys., 2008, 104, 034907.

52 A. M. Rao, X. H. Ji and T. M. Tritt, MRS Bull., 2006, 31, 218-223.

53 W. Q. Ao, W. A. Sun, J. Q. Li, F. S. Liu and Y. Du, J. Alloys Compd., 2009, 475, L22-L24.

54 L. Wang, G. Chen, Q. Wang, H. J. Zhang, R. C. Jin, D. H. Chen and X. B. Meng, J. Phys. Chem. C, 2010, 114, 5827-5834.

55 C. J. Liu, G. J. Liu, C. W. Tsao and Y. J. Huang, J. Electron. Mater., 2009, 38, 1499-1503.

56 M. S. Milan Paunovic, Fundamentals of Electrochemistry, Wiley, 2nd edn, 2006.

57 M. S. Sander, R. Gronsky, T. Sands and A. M. Stacy, Chem. Mater., 2003, 15, 335-339.

58 L. Li, Y. W. Yang, X. H. Huang, G. H. Li and L. D. Zhang, Nanotechnology, 2006, 17, 1706-1712.

59 S. H. Li, M. S. Toprak, H. M. A. Soliman, J. Zhou, M. Muhammed, D. Platzek and E. Muller, Chem. Mater., 2006, 18, 3627-3633.

60 G. R. Li, F. L. Zheng and Y. X. Tong, Cryst. Growth Des., 2008, 8, $1226-1232$

61 S. H. Li, H. M. A. Soliman, J. Zhou, M. S. Toprak, M. Muhammed, D. Platzek, P. Ziolkowski and E. Muller, Chem. Mater., 2008, 20, 4403-4410.

62 S. H. Li, Y. B. Liang, J. Qin, M. Toprak and M. Muhammed, J. Nanosci. Nanotechnol., 2009, 9, 1543-1547.

63 C. G. Jin, X. Q. Xiang, C. Jia, W. F. Liu, W. L. Cai, L. Z. Yao and X. G. Li, J. Phys. Chem. B, 2004, 108, 1844-1847.

64 M. Martin-Gonzalez, A. L. Prieto, R. Gronsky, T. Sands and A. M. Stacy, Adv. Mater., 2003, 15, 1003-1005.

65 M. Martin-Gonzalez, G. J. Snyder, A. L. Prieto, R. Gronsky, T. Sands and A. M. Stacy, Nano Lett., 2003, 3, 973-977.

66 Y. Y. Wu, R. Fan and P. D. Yang, Nano Lett., 2002, 2, 83-86.

67 B. Yoo, F. Xiao, K. N. Bozhilov, J. Herman, M. A. Ryan and N. V. Myung, Adv. Mater., 2007, 19, 296-299.

68 L. Li, G. H. Li, Y. Zhang, Y. W. Yang and L. D. Zhang, J. Phys. Chem. B, 2004, 108, 19380-19383. 
69 S. Gorer, A. Albuyaron and G. Hodes, Chem. Mater., 1995, 7, $1243-$ 1256.

70 S. K. Sarkar, S. Kababya, S. Vega, H. Cohen, J. C. Woicik, A. I. Frenkel and G. Hodes, Chem. Mater., 2007, 19, 879-888.

71 S. Gorer and G. Hodes, J. Phys. Chem., 1994, 98, 5338-5346.

72 G. Hodes, Phys. Chem. Chem. Phys., 2007, 9, 2181-2196.

73 Y. X. Zhao, P. Larimer, R. T. Pressler, B. W. Strowbridge and C. Burda, Angew. Chem., Int. Ed., 2009, 48, 2407-2410.

74 X. F. Qiu, L. N. Austin, P. A. Muscarella, J. S. Dyck and C. Burda, Angew. Chem., Int. Ed., 2006, 45, 5656-5659.

75 X. F. Qiu, Y. X. Zhao, I. M. Steward, J. S. Dyck and C. Burda, Dalton Trans., 2010, 39, 1095-1100.

76 J. P. Ge and Y. D. Li, J. Mater. Chem., 2003, 13, 911-915.

77 Q. Li, Y. Ding, M. W. Shao, J. Wu, G. H. Yu and Y. T. Qian, Mater. Res. Bull., 2003, 38, 539-543.

78 Y. Y. Zheng, T. J. Zhu, X. B. Zhao, J. P. Tu and G. S. Cao, Mater. Lett., 2005, 59, 2886-2888.

79 J. J. Zhu, H. Wang, S. Xu and H. Y. Chen, Langmuir, 2002, 18, 3306-3310.

80 J. J. Zhu, S. T. Aruna, Y. Koltypin and A. Gedanken, Chem. Mater., 2000, 12, 143-147.

81 C. Burda, X. B. Chen, R. Narayanan and M. A. El-Sayed, Chem. Rev., 2005, 105, 1025-1102.

82 M. R. Dirmyer, J. Martin, G. S. Nolas, A. Sen and J. V. Badding, Small, 2009, 5, 933-937.

83 M. V. Kovalenko, B. Spokoyny, J. S. Lee, M. Scheele, A. Weber, S. Perera, D. Landry and D. V. Talapin, J. Am. Chem. Soc., 2010, 132, 6686-6695.

84 W. J. Liang, A. I. Hochbaum, M. Fardy, O. Rabin, M. J. Zhang and P. D. Yang, Nano Lett., 2009, 9, 1689-1693.

85 W. J. Liang, O. Rabin, A. I. Hochbaum, M. Fardy, M. J. Zhang and P. D. Yang, Nano Res., 2009, 2, 394-399.

86 A. Purkayastha, S. Kim, D. D. Gandhi, P. G. Ganesan, T. BorcaTasciuc and G. Ramanath, Adv. Mater., 2006, 18, 2958-2963.

87 A. Purkayastha, Q. Y. Yan, M. S. Raghuveer, D. D. Gandhi, H. F. Li, Z. W. Liu, R. V. Ramanujan, T. Borca-Tasciuc and G. Ramanath, Adv. Mater., 2008, 20, 2679-2683.

88 M. Scheele, N. Oeschler, K. Meier, A. Kornowski, C. Klinke and H. Weller, Adv. Funct. Mater., 2009, 19, 3476-3483.

89 J. J. Urban, D. V. Talapin, E. V. Shevchenko, C. R. Kagan and C. B. Murray, Nat. Mater., 2007, 6, 115-121.

90 R. Y. Wang, J. P. Feser, X. Gu, K. M. Yu, R. A. Segalman, A. Majumdar, D. J. Milliron and J. J. Urban, Chem. Mater., 2010, 22, 1943-1945.

91 R. Y. Wang, J. P. Feser, J. S. Lee, D. V. Talapin, R. Segalman and A. Majumdar, Nano Lett., 2008, 8, 2283-2288.

92 W. W. Zhou, J. X. Zhu, D. Li, H. H. Hng, F. Y. C. Boey, J. Ma, H. Zhang and Q. Y. Yan, Adv. Mater., 2009, 21, 3196-3200.
93 N. Ziqubu, K. Ramasamy, P. V. S. R. Rajasekhar, N. Revaprasadu and P. O'Brien, Chem. Mater., 2010, 22, 3817-3819.

94 Y. X. Zhao and C. Burda, ACS Appl. Mater. Interfaces, 2009, 1, $1259-1263$.

95 J. J. Urban, D. V. Talapin, E. V. Shevchenko and C. B. Murray, J. Am. Chem. Soc., 2006, 128, 3248-3255.

96 W. G. Lu, J. Y. Fang, K. L. Stokes and J. Lin, J. Am. Chem. Soc., 2004, 126, 11798-11799.

97 W. K. Koh, A. C. Bartnik, F. W. Wise and C. B. Murray, J. Am. Chem. Soc., 2010, 132, 3909-3913.

98 J. S. Son, K. Park, M. K. Han, C. Kang, S. G. Park, J. H. Kim, W. Kim, S. J. Kim and T. Hyeon, Angew. Chem., Int. Ed., 2011, 50, 1363-1366.

99 M. Scheele, N. Oeschler, I. Veremchuk, K. G. Reinsberg, A. M. Kreuziger, A. Kornowski, J. Broekaert, C. Klinke and H. Weller, ACS Nano, 2010, 4, 4283-4291.

100 Y. X. Zhao, J. S. Dyck, B. M. Hernandez and C. Burda, J. Am. Chem. Soc., 2010, 132, 4982-4983.

101 Y. X. Zhao, J. S. Dyck, B. M. Hernandez and C. Burda, J. Phys. Chem. C, 2010, 114, 11607-11613.

102 G. S. Nolas, J. Sharp and H. J. Goldsmid, Thermoelectrics: Basic Principles and New Materials Developments, Springer, Berlin, Heidelberg, 2001.

103 D. M. Rowe, CRC Handbook of Thermoelectrics, CRC, Boca Raton, FL, 1995

104 N. Gothard, X. Ji, J. He and T. M. Tritt, J. Appl. Phys., 2008, $103,4$.

105 A. Purkayastha, F. Lupo, S. Kim, T. Borca-Tasciuc and G. Ramanath, Adv. Mater., 2006, 18, 496-500.

106 F. H. Li and W. Wang, Appl. Surf. Sci., 2009, 255, 4225-4231.

107 B. Zhou, X. H. Li and J. J. Zhu, Cryst. Growth Des., 2007, 7, 22762278.

108 K. Park, F. Xiao, B. Y. Yoo, Y. Rheem and N. V. Myung, J. Alloys Compd., 2009, 485, 362-366.

109 I. Y. Erdogan and U. Demir, J. Electroanal. Chem., 2009, 633, $253-$ 258.

110 C. G. Jin, G. Q. Zhang, T. Qian, X. G. Li and Z. Yao, J. Phys. Chem. $B, 2005,109,1430-1432$.

111 J. Y. Yang, W. Zhu, X. H. Gao, S. Q. Bao, M. Fan, X. K. Duan and J. Hou, J. Phys. Chem. B, 2006, 110, 4599-4604.

112 C. L. Chen, Y. Y. Chen, S. J. Lin, J. C. Ho, P. C. Lee, C. D. Chen and S. R. Harutyunyan, J. Phys. Chem. C, 2010, 114, 3385-3389.

113 R. Vaidyanathan, S. M. Cox, U. Happek, D. Banga, M. K. Mathe and J. L. Stickney, Langmuir, 2006, 22, 10590-10595.

114 Q. Yao, L. D. Chen, W. Q. Zhang, S. C. Liufu and X. H. Chen, ACS Nano, 2010, 4, 2445-2451.

115 K. C. See, J. P. Feser, C. E. Chen, A. Majumdar, J. J. Urban and R. A. Segalman, Nano Lett., 2010, 10, 4664-4667. 